\title{
A Cross-cultural Analysis of Brand Personality: Comparisons of China's and the US Energy Companies' English Websites
}

\author{
Xiaohui Shan \\ China Women's University, Beijing, China \\ Qian Wang \\ China Women's University, Beijing, China
}

\begin{abstract}
With the rapid development of economic globalization, projecting a positive image overseas and creating world famous brands have become vital to enhance industrial and national core competencies and execute the "Going out" strategy. To achieve the goals, corporates attach significance to establish and maintain corporate websites in view of its convenience, autonomy and interactivity while encountering cross-cultural challenges. This study employs corpus analytical tools to conduct content analysis on the existing cross-cultural differences and the linguistic and cultural features, between Chinese and US energy companies' websites based on Aaker's brand personality framework and Hofstede's cultural dimension theory. Findings reveal that there is a significant difference between occurrence frequencies of brand personality dimensions between China and US, and their websites linguistic discrepancies are relevant to their cultural differences. The study may provide meaningful implications on employing linguistic theories and methods to conduct multidisciplinary studies on corporate communication online.
\end{abstract}

Index Terms - cross-cultural, brand personality, corporate website, China, the US

\section{INTRODUCTION}

In the year of 2015, energy companies on Fortune Global 500 has a slight increase by 0.49 percent in total operating income, but the overall decreased by 14.76 percent in profits margins, which can be attributed to several uncontrollable factors including sluggish global economic recovery, general decline in commodity prices, and China's "New Normal". Although the total income and profit of Chinese energy companies on the ranking list have increased by 6.8 and 11.7 percent respectively, their roles in the global market will be further highlighted in the future. The whole industry' profitability has decreased significantly, operating income and profits both declined, with only one more company getting ranked among the 500 list. Oil and gas companies still account for the largest proportion, whose profitability has dropped substantially, while that of power companies has improved. Minerals and coal companies have suffered the severest decline in profits that greatly bring down their rankings. Considering the development of the world economy, we expect energy companies will continue to play an important role for quite a long period of time, especially in developing countries, since energy resources are the main power and material source, as well as engines of economic development and employment. However, the booming of energy alternatives and environmental protection has been worsening the situation of energy companies. To survive this, energy industry has become more eager for corporate identity marketing and branding, seeing corporate brands as a guarantee of quality and insurance against the irreplaceability. Therefore, the energy companies are prompted to enhance branding awareness to gain a long-term competitive advantage.

Corporate brand personality, as a key component of corporate image and an outcome of corporate branding (Keller \& Richey, 2006), is significantly related corporate communications in websites (Okazaki, 2006), which combine multimodal elements (text, image, video, interactive functions, etc. Simões (2015) reveals that companies utilize a consistent online presence to convey their brands and build stakeholders relationships, especially for those operate globally. According to Breeze (2013), corporate identity, currently multidimensional and dynamic, is realized through corporate communication discourse. As a powerful and accessible means of corporate communication, corporate website helps translating corporate identity into corporate image and finally corporate reputation (Dowling, 2001). For a long time, foreign-market-oriented companies have been struggling with two choices, whether to standardize global websites or to adapt their websites to local cultural preferences (Chao, Singh \& Chen, 2012). A much larger proportion of researchers have validated the effectiveness of localizing corporate websites instead of globalizing them with empirical evidences covering both developed and developing countries. Practitioners also agree that cultural adaptation of corporate websites can ensure successful marketing campaigns online (Vence, 2005), moreover, they need guidance to localize corporate websites culturally as well as linguistically.

Previous studies tend to focus on investigating themes and designs of corporate websites employing marketing 
theories, or corporate communication, while linguistic exploration of online corporate communication discourse is not yet adequate, especially from China's perspective and a lot of attention has been paid to online branding and corporate identity construction via its website, especially as an aspect of professional communication, there is only very little research that looks at the processes involved in these activities from a quantitative linguistic analytical perspective or in corporate websites localization construction, which is seriously out of accordance with the Belt and Road Initiative and the rapid growth of overseas direct investment. To fill this gap, we make this cross-cultural study of "about us" in Chinese and US energy companies' websites based on the Aaker's dimensions of corporate brand personality by employing computerized content analysis. Brand personality is assessed in terms of what the company itself intends to convey to the public. Some managerial best practices are proposed for Chinese companies to effectively use brand personality dimensions to develop a unique corporate identity in the international market.

\section{LITERATURE REVIEW}

\section{A. Hofstede's Cultural Dimensions Theory}

Several studies, based on Hofstede's researches, deal with cultural differences in websites. According to Hofstede, national cultures can be measured according to four dimensions: the first one is power distance (PD), the degree of inequality in power between a less powerful individual and a more powerful other. Specifically, high PD cultures, e.g. those in Asia or Latin America, are characterized by wide inequalities in power systems, centralized and hierarchical structures, and dependence on higher ranked staff (e.g. supervisors). In contrast, for example, Northern European countries are deemed low PD cultures. The second one is individualism vs collectivism (IDV). The dimension characterizes collectivist cultures as relationship and group orientated. In contrast, individual orientated cultures are those in which people are expected to take greater responsibility, and where attention is drawn towards the individual. The third one is femininity vs masculinity (MAS). Masculinity is considered to describe a culture in which assertiveness, achievement and material possessions are seen as masculine goal-orientated behavior. In contrast, femininity is more modest, tender, able and willing to reach compromises, as well as concerned with the quality of life. Uncertainty avoidance (UAI) describes a lack of tolerance for uncertainty and ambiguity. Highly structured rules within organizations, or intolerance towards groups or individuals who have different ideas or behavior styles, characterized high uncertainty avoidance cultures. Moreover, individuals are expected to take and accept risks and responsibilities, as well as demonstrate independence in their own roles (Hofstede, 1984).

Websites cultural markers have a positive association with the Hofstede's cultural dimensions: when the Hofstede's cultural dimensions differ, diversity arises among cultural markers of websites. This result strongly recommends that culture awareness is necessary to improve management of cross-cultural online communication (Burgmann, Kitchen \& Williams, 2006). Several studies analyze content of websites according to a cross-cultural perspective (Burnett \& Buerkle, 2004), cultural adaptation of websites improving effectiveness of companies' internationalization strategies. Recent studies stress that, in globalized markets, the ability to manage cultural diversity is a strategic competence that companies have to employ for designing their websites. Other researches analyze websites of transnational companies and show that their operating in high and low context cultures dominated by indirect communication. Several studies focus on website cultural indicators, but only few researches are conducted on energy companies' websites.

\section{B. Corporate Identity and Brand}

A corporate identity is the manner which a corporation, firm or business presents themselves to the public, such as customers and investors as well as employees. It is a primary task of corporate communication to maintain and build this identity to accord with and facilitate business objectives. Typically it is visually manifested by way of branding and the use of trademarks, but also includes things like product design, advertising, public relations (Judith, 2001), which gives organizations their distinctiveness. Corporate identity is more than the visual identity of the company, and goes beyond the internal reality defined by the different cultures that shape the company's personality. Corporate brand is grounded on the corporate identity. The systemic alignment of corporate identity could form a solid and positive corporate reputation, viewed by all stakeholders of a company over time and key source of the competitive advantage. Therefore, corporate reputation cannot be managed, but can be improved by corporate identity management. Corporate website as a more powerful and accessible means of corporate communication helps translating corporate identity into corporate image and finally corporate reputation. Therefore, corporate website has received increasing attention of researchers.

\section{Corporate Brand Personality Scale}

Brand personality has been widely studied in marketing for many years. Aaker introduced a five-dimensioned brand personality scale in 1997, which disclosed five distinct and robust personality categories: sincerity, excitement, competence, sophistication and ruggedness, represented by 15 attributes and 42 items (Table 1), Sincerity shares many attributes with Agreeableness. Excitement is defined with energy and activity of Extraversion. Competence denotes dependability and achievement like Conscientiousness. Sophistication and Ruggedness capture more aspirational images associated with wealth and status. This study is theoretically based on Aaker's brand personality framework. Aaker's theory is the most well-known scale and has been widely reviewed, extended and replicated by many 
researches for examining companies' online identify especially mission and vision statements, which support its validity, reliability and international practicability. Another reason to choose Aaker's scale is that it is linguistically accessible.

TABLE 1:

WEBSITE BRAND PERSONALITY EVALUATION CRITERIA (AAKER, 1997)

\begin{tabular}{|c|c|c|c|}
\hline Dimensions & Traits & Example of words & Number of words \\
\hline \multirow{3}{*}{ Sincerity } & - $\quad$ Down-to-earth & - Down-to-earth, Family-oriented, Small-town & \multirow[b]{3}{*}{174} \\
\hline & Honest & Honest, Sincere, Real & \\
\hline & Wholesome & Wholesome, Original & \\
\hline \multirow{2}{*}{ Excitement } & Daring & Daring, Trendy, Exciting & \multirow{2}{*}{143} \\
\hline & - $\quad$ Spirited & Spirited, Cool, Young & \\
\hline \multirow{3}{*}{ Competence } & Reliable & Reliable, Hardworking, Secure & \multirow{3}{*}{168} \\
\hline & Intelligent & Intelligent, Technical, Corporate & \\
\hline & Successful & Successful, Leader, Confident & \\
\hline \multirow{2}{*}{ Sophistication } & - $\quad$ Upper class & - Upper-class, Glamorous, Good-looking & \multirow{2}{*}{174} \\
\hline & - $\quad$ Charming & - $\quad$ Charming, Feminine, smooth & \\
\hline
\end{tabular}

Website is the place where stakeholders have the first contact with companies (Booth, 2011), so companies attempt stronger online presence to convey and articulate brand information. Researchers and practitioners have stressed the objectives and application of online branding and brand personality. Online brand personality is formed by describing corporate identity on corporate websites. Brands are carriers of universal and specific cultural meanings, and cultural values and beliefs can affect brand personality and consumer satisfaction of goods and services (Arnould, 2005). Brand identity is expected to adjust to the environmental context. Brand image is affected by culture. Aaker reveals that culture has an influence on customer's perception of brand personality and finds that culturally distinct dimensions as well as cross-culturally similar dimensions (sincerity, excitement, competence and sophistication). Based on the above, we put forward Research Questions:

RQ 1: To what extent are Chinese energy companies different from the US with respect to languages describing brand personality dimensions in "about us" section of corporate websites?

RQ 2: What particular personality traits shall Chinese energy companies present online to improve their corporate identity?

\section{RESEARCH Methodology}

\section{A. Samples}

The websites of Chinese and US energy companies serve as the sample for this study. China and the US are chosen for four reasons. First, as the top two economies, China and US are comparable in terms of company numbers, sizes and performances. Second, nowadays China introduces the "going out" strategy to encourage its companies to invest overseas, with a main objective to promote brand recognition of Chinese companies in the international market. Third, their bilateral trade and investment volume have been growing steadily accounting for an overwhelming proportion in the world. Fourth, these two countries are widely different in terms of culture (see Fig. 1).

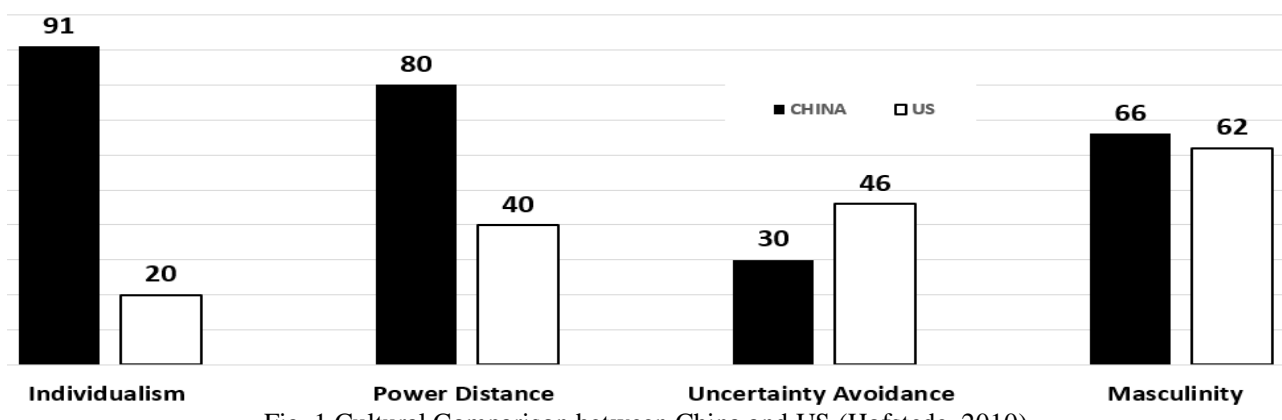

Fig. 1 Cultural Comparison between China and US (Hofstede, 2010)

Considering that different settings may result in different personality dimensions, we limit the study to one single industry to control disturbing variables. Energy industry is chosen because energy companies are likely to utilize more resources to communicate distinctive online brand personalities as, and tend to be good at websites informing customers in a well-organized and emerging manner.

As many similar studies use Fortune Global 500 list for a sampling frame, this study chooses this list based on the assumption that companies ranked on this list have managed to create positive images and English websites. The total 
number of Chinese and US energy companies listed on the Year 2015 Fortune Global 500 is 25 and 18 respectively. Among the 25 Chinese companies, 9 websites are not available. Finally we have 16 energy companies from China and the US respectively. Then, we use the well-recognized search engine Google for these companies' English websites. In spite of the limited sample size, this study takes its advantage to explore rich details of personality, which cannot be captured by a quantitative analysis of a large sample, thereby to offer very helpful guidelines for practitioners. Actually an increasing number of researchers utilize a qualitative approach (Arora \& Stoner, 2009).

\section{B. Unit of Analysis}

The unit of analysis of this study is "about us" section online. Given the sheer size of corporate websites, it is practicable to focus on one section in websites. A number of researchers chose "about us" section, in view that it is aimed to build corporate identities for all stakeholders (Abdullah, Nordin \& Aziz, 2013). In "about us" section, the company has to pay particular attention to select information and organize language to explain company history, culture and value, social responsibility, location, business and industry line, newsletter, rating and awards, management profile, financial status, employment, and especially vision and mission statements which indicate the essence and uniqueness of company's existence.

With the concern that websites may change we set a specific, albeit random, week, from September 5 to September 11, 2016, for data collection. To narrow the unit of analysis even further down, the corpus compiled includes the landing pages of the "about us" sections and the landing pages of all their subsections. The rationale behind this choice is that landing pages determine whether visitors will continue to browse the section. Macromedia, Flash movies, and any short-term information such as news and announcements are ignored (Rogers, Van Buskirk \& Zechman). The files of the pages are saved and converted into a text corpus of a total of 122 thousand words, which excludes non-machine-readable text, e.g. text included in images. Appendix list the sample companies, their website links, service categories and the number of pages examined.

\section{Content Analysis}

Content analysis is a widely used tool for conducting objective, systematic and quantitative analysis of communication content. Several previous studies have used content analysis for analyzing corporate websites communications (Singh \& Pereira, 2005). To quantify and qualify the five personality dimensions in "about us", we use content analysis with the aid of a text mining and analyzing software called WordStat, which theoretically relies on a well-established word list with the strength of continuity, normalization and objectivity (Davies et al., 2001). Also with the brand personality dictionary developed by Opoku, Abratt and Pitt, we employ WordSmith to identity most frequently used words for each dimension and their concordances, which facilitate our in-depth cross-cultural qualitative analysis of the websites texts.

\section{FINDINGS AND DISCUSSION}

The purpose of this study is to identify and compare patterns of language choices expressing the brand personality dimensions in Chinese and US energy companies' websites. To this end, "about us" texts in 32 websites are mined and analyzed as follows.

\section{A. Descriptive Analysis}

The study reveals two unexpected findings. First, Chinese companies don't quite differ from US companies with respect to "about us" content in English websites and presence of brand personality. As shown in Table 3, the occurrence frequencies of company history, mission and vision, maps and locations, corporate social responsibility and awards in the two countries are quite close. Recruiting information appears more in "about us" in US websites, while more in a special Career section in China's. There are more culture and ethics codes and customer affairs in US websites than in China's, which can be explained by US companies' strong sense of social responsibility, American melting pot of different races and sophisticated customer relationship management.

The statistical analysis provides evidence (see Table 3) that the website texts of Chinese energy companies (mean frequency 13.76) shows greater concern with brand personality, particularly the Competence dimension, as compared with US (mean frequency 7.03). This can be explained that Chinese energy companies suffer much more pressure to going-out competing with foreign counterparts, and the government has been practicing liberalization and opening-up policies. 
TABLE 2:

“ABOUT US” PROFILE IN SAMPLE COMPANIES' WEBSITES

\begin{tabular}{lll}
\hline "about us" Content & China & US \\
\hline History & 15 & 16 \\
Values, Culture, Ethics codes & 8 & 13 \\
Vision, Mission statement & 8 & 9 \\
Corporate social responsibility & 4 & 5 \\
Locations, Map & 4 & 5 \\
Operations, Business line, Industry & 7 & 4 \\
Newsletter, Press release & 2 & 6 \\
Financial information & 3 & \\
Ad. Gallery & 2 & 15 \\
CEO, Pictures, Biography & 11 & \\
Career, Employment & 3 & \\
Sponsorship (education, sports, arts, etc.) & 0 & \\
Awards rating & 7 & 0 \\
Consumer Affairs, Club Community & 0 & \\
Video & 6 & \\
\end{tabular}

TABLE 3:

DISTRIBUTION OF BRAND PERSONALITY DIMENSIONS ACROSS COUNTRIES

\begin{tabular}{|c|c|c|c|c|c|}
\hline \multirow{2}{*}{$\begin{array}{l}\text { Brand Personality } \\
\text { Dimension }\end{array}$} & \multicolumn{2}{|c|}{ CHINA $(n=16)$} & \multicolumn{2}{|c|}{ US $(n=16)$} & \multirow{2}{*}{$\chi^{2}$ test } \\
\hline & Total & Mean & Total & Mean & \\
\hline Competence & 710 & 44.38 & 269 & 16.81 & $9008.615^{* * * *}$ \\
\hline Sincerity & 192 & 12 & 150 & 9.38 & 2588.251 *** \\
\hline Excitement & 120 & 7.5 & 90 & 5.63 & $1623.238 * * *$ \\
\hline Ruggedness & 41 & 2.56 & 28 & 1.75 & $558.754 * * *$ \\
\hline Sophistication & 38 & 2.38 & 25 & 1.56 & $573.429 * * *$ \\
\hline Frequency mean & 13.76 & & 7.03 & & \\
\hline
\end{tabular}

In addition, as shown in Table 3, these two countries also show similar patterns in personality dimension expressions, with many more traits of Competence and Sincerity than Excitement, Ruggedness and Sophistication. Chun \& Davies found that Competence was a dominating dimension in online Mission and Vision statements of the energy industry, followed by Sincerity, Excitement, Ruggedness, and NO Sophistication was identified. Sung \& Tinkham also reveal that brand personality structure can substantiate similar features in both western and eastern cultures (Sung \& Tinkham, 2005).

Specifically, there are differences between the distributions of brand personality dimension across countries. To more accurately position the 32 websites in relation to the five brand personality dimensions, we use the WordStat to output a correspondence analysis graph (see Fig. 2), which is practicable with strong dependency of variables from cross-tabulation test (see table 5). Corporate website is clustered near to the brand personality dimension that it mostly communicates on their websites. For example, Competence is mostly communicated on the websites of Chinese energy companies, like Ansteel Group and Baosteel Group, whereas Sincerity, Excitement and Ruggedness conveyed by US companies, like Valero Energy and ConocoPhillips. Sinopec is located loosely between Sincerity and Competence, indicating a weaker correspondence. Tesoro appears to weakly promote Sincerity. None of these websites communicate Sophistication strongly, but China National Aviation Fuel Group (CNAF) is an exception, indicating that it might not be a complete website comparing with other companies. Obviously, most companies are clustered near to the Competence brand personality dimension and the center of the map that they mostly communicate on their websites (located in the blue circle). Therefore, suggesting some similarities are existing in these companies and both China and America companies' websites are more attaching importance on Competence. 


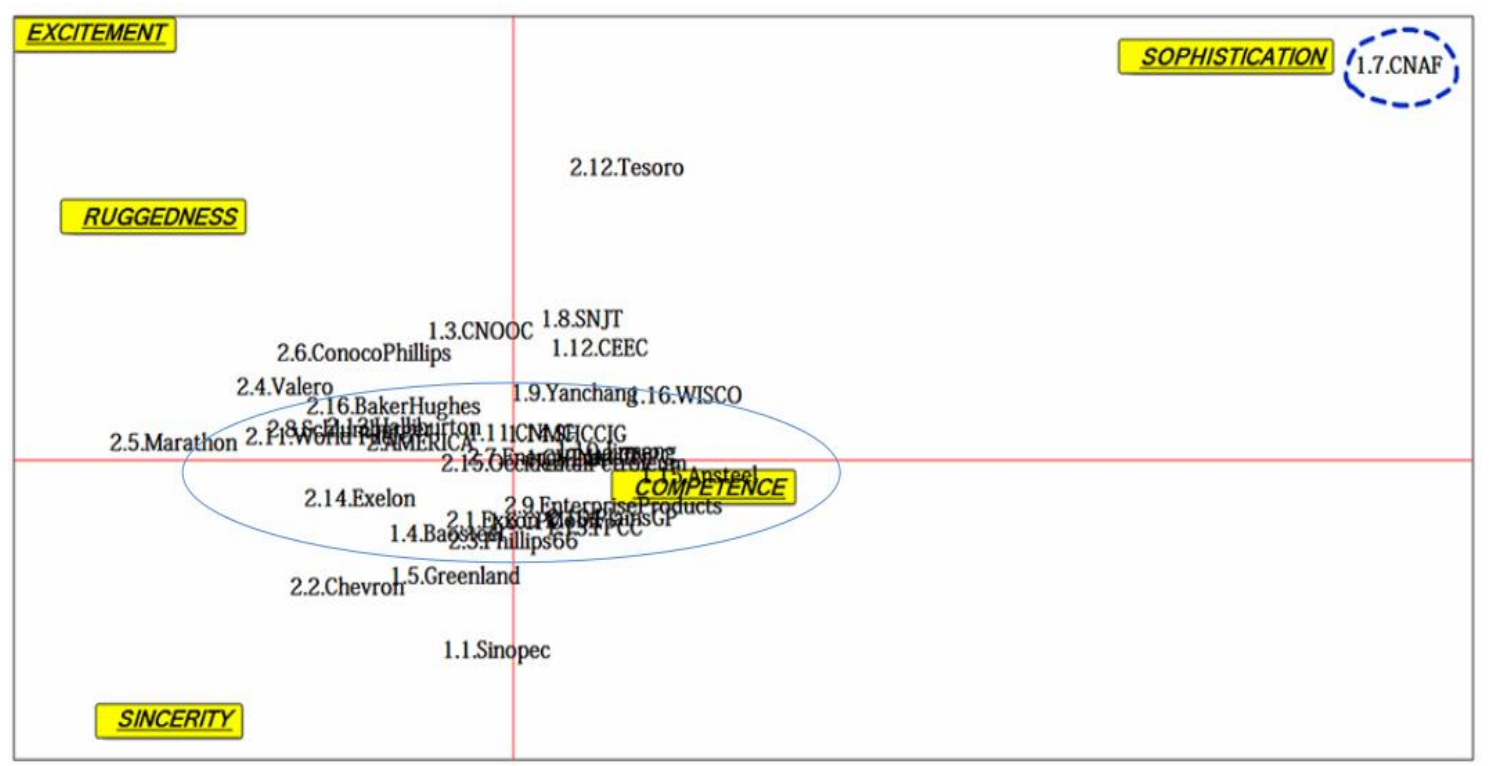

Fig. 2 Correspondence Analysis Map of brand personality traits observed in Websites messages of China and US

\section{B. Discussion}

Although globalization makes people more similar, to some extent Aaker's brand personality dimensions differ across cultural contexts with Sincerity, Excitement, Competence, Sophistication, and Ruggedness connoting both culture-specific and culture-universal meaning. Culture-universal meaning usually exists in the more concrete qualities of brands that present personality like Competence and Sincerity, while culture-specific meaning typically resides in the more abstract qualities of brands that communicate such personality like Ruggedness and Sophistication (Aaker, Benet-Martínez \& Garolera, 2001).

Corporate identity is viewed as a combination of soul, persona and spirit of corporate personality, and shall be managed differently considering linguistic and cultural differences. The linguistic differences of Chinese and US online brand personality expressions can be attributed to their cultural differences. Although Competence is the most presented dimension both in Chinese and US websites, US companies distribute with Sincerity, Excitement and Ruggedness in a relatively larger percentage than China. These four brand personality dimensions are over ignored in Chinese energy companies' websites, which can also be supported by Figure 2. Excitement, Sophistication and Ruggedness have been found in significant presence by previous researches concerning the US brands, which have addressed brand personality dimensions in companies' websites with the underlying idea that personality attributes lead to corporate brand differentiation. 错误! 未定义书签。] It is hard to verify findings with Chinese companies since there are few researches on brand personality dimension in Chinese companies' websites.

- Competence Dimension

Competence is the dominating dimension in both China's and US websites, pertaining to concepts like responsibility, dependability, achievement and security. Companies tend to emphasize their Competence in their Mission and Vision statements, especially reliability and leadership in their field. Most energy companies are strongly associated with Competence as shown in Table 3 and Fig.2. It is natural with the facts that energy companies offering resources services are much more professional knowledge intensive, and competent brands are mostly perceived by consumers with expertise and quality.

TABLE 4:

KEY WORDS AND FREQUENCIES ASSOCIATED WITH COMPETENCE IN “ABOUT US” OF CHINESE AND US ENERGY COMPANIES’ WEBSITES

\begin{tabular}{llll}
\hline Dimension & Frequency Rank & CHINA & US \\
\hline & 1 & Industry (143) & Production (50) \\
Competence & 2 & Production (112) & Industry (35) \\
& 3 & Enterprise (86) & Partnership (27) \\
& 4 & Industrial (51) & Responsible (13) \\
\hline
\end{tabular}

To examine cultural-specific differences in language choices, we retrieve words listed under the Competence dimension and present the most frequently used in Table 4. It is found that many more Partnership and Responsible used in the US texts, while Enterprise and Trade in the Chinese texts. Some related sentences are retrieved and presented below randomly. 
-...to be the global energy company most admired for its people, partnership and performance...

-...the company's master limited partnership is an integral asset in the portfolio...

-... and practices designed to enable safe, secure and environmentally responsible operations...

CHINA

- To be a transnational steel group with the most international competitive power and the leading enterprise of the Chinese steel industry.

-...be loyal to the enterprise, honor the commitments made before the partners and be responsible for the society and the country.

- PetroChina International deals with international trade in crude oil and about 100 kinds of refined and chemical products to and from over 80 countries...

According to concordances retrieved, it is evident that Partnership is a sign of collective and Responsible is for describing corporate social responsibilities (CSR). Singh \& Matsuo found that CSR was a cultural marker of Collectivism instead of Individualism in corporate websites. In general, the core element of individualism is the assumption that individuals are independent of one another, focus on rights above duties, and concern for oneself. 错 误! 未定义书签。](p.413) However, although the US is categorized as individualistic culture (scored 91, see Fig.1), a large majority of US companies disclose CSR information in their websites. In spite of being characterized as collectivism culture (scored 20), Chinese companies are still in quite dark ages with regard to disclosing online CSR information. In this case, the fact that CSR is a well-acknowledged and promoted marketing strategy in the US has surpassed the impact of cultural dimension to result in this phenomenon.

Enterprise and Trade appear frequently in Chinese websites, which reflects that China energy companies are going-out, import and export trade scales are extending during the process of economic globalization and trade integration, and the government has been practicing liberalization and opening-up policies.

- Sincerity Dimension

Sincerity dimension, articulated with a list of 174 words encompassing aspects of natural, good and acceptance, is the second important personality both in Chinese and US websites. Sincere brands share family-related associations, trustworthiness and high morals (Maehle, Otnes \& Supphellen, 2011). Rexha identified the lack of trust has been regarded as one of the major factors to influence customers. As shown in Table 3, the Sincerity presence of Chinese companies is significantly higher than that of American companies. American companies display relatively higher presence of Sincerity as compared to other dimensions.

TABLE 5:

KEY WORDS AND FREQUENCIES ASSOCIATED WITH SINCERITY IN “ABOUT US” OF CHINESE AND US ENERGY COMPANIES’ WEBSITES

\begin{tabular}{llll}
\hline Dimension & Frequency Rank & CHINA & US \\
\hline \multirow{4}{*}{ Sincerity } & 1 & Natural (32) & Natural (50) \\
& 2 & Standard (20) & Reod (9) \\
& 3 & Good (18) & Common (8) \\
& 4 & Real (14) & Understanding (7) \\
\hline
\end{tabular}

As shown Table 5, texts of the two countries have less overlap, and share only two words, Natural and Good. Standard, Real and Honest are more frequently used in Chinese websites, and Reliable, Common and Understanding in US websites. Retrieved sentences are randomly listed below.

US

-...our local geomarket teams work side by side with customers to engineer reliable...

-...with men and women of many nationalities and backgrounds working together and sharing common objectives.

- This document is designed to assist employees in understanding and applying these elements in order for Schlumberger to continue its success...

CHINA

- During the reporting period, we have 3 mines reached the national quality standard, 12 reached the first-level provincial quality standard...

-...be meticulous, know the real situation, tell the truth, adopt real measures, do real things, and pay attention to the results...

- Baosteel is firmly determined to pursue its strategic goal of being the most competitive enterprise in the world, and shall also be an honest, friendly...

Energy companies are expected to display more sincere items to relieve customers' risk concern since the US culture has high Uncertainty Avoidance (UAI, US 46, China 30, in Fig.1) tending to avoid risks by employing more control measures. As above mentioned America companies use many Reliable and Understanding to avoid uncertainty.

As a culture with high PD (scored 80, see Fig.1), Chinese companies use many Standard, Real and Honest to elaborate their hierarchy management and affiliation with administrative governments. Furthermore, like China, where individualism is weak, consumers are more responsive to social brand-image strategies, emphasizing group membership, standard requirements and affiliation benefits.

- Excitement Dimension 
Excitement is the third dimension expressed both in Chinese and US websites, related to sociality, energy and activity. Brands with these traits offer consumers the opportunity to experience exciting feelings and are related to special 'exciting' occasions (Opoku \& Hinson, 2006). Park defined brand image in terms of three dimensions: functional, social and sensory, and found that emphasis on functional strategies are enhanced in less developed countries, and social and sensory brand images are stressed in advanced economies. Excitement personality dimension is for building sensory brand image with a relatively higher presence in US websites than China. In countries characterized by strong individualism, brand strategies are more effective emphasizing variety, novelty and experiential needs.

TABLE 6:

KEY WORDS AND FREQUENCIES ASSOCIATED WITH EXCITEMENT IN “ABOUT US” OF CHINESE AND US ENERGY COMPANIES' WEBSITES

\begin{tabular}{llll}
\hline Dimension & Frequency Rank & CHINA & US \\
\hline & 1 & Modern (20) & Individual (13) \\
Excitement & 2 & Young (14) & Independent (11) \\
& 3 & Innovative (12) & Innovative (10) \\
& 4 & Independent (9) & Unique (6) \\
& 5 & Autonomous (7) & Specific (5) \\
\hline
\end{tabular}

There is less overlap between the two countries' key word lists (Table 6), with only two similar words. Concordances of Individual, Unique, Modern and Young are presented below.

US

- We believe a learning environment is the way to achieve the full potential of each individual and the company.

- We expect development throughout each individual's career by a combination of individual and company commitment...

- We respond to each customer's unique business needs with personalized service...

CHINA

- CNMC has managed to merge traditional Chinese culture with modern concept on scientific management and found out a cultural path for excellent enterprises suitable for itself...

-...implements a young $R \& D$ talents training project to strengthen the training of young technological managers. The first batch of 136 young employees are selected for a three-year training plan which aims to cultivate a sustainable team of technological pioneers and middle and high level technological managers.

Belonging to a typical individualistic society, the US companies stress Individual and pay attention to Unique individual needs to construct a favorable corporate brand personality online. As a high PD as well as a past time oriented society, Chinese tend to emphasize long history as a sign of higher social status and achievement. As a society longing for fast development, Modern is expected and appreciated at the same time.

- Ruggedness and Sophistication Dimension

Unlike the first three dimensions resembling human personality, Ruggedness and Sophistication are associated with wealth and status, or American individualism, which are more culturally specific dimensions. 错误! 未定义书签。] Although these two dimensions are the least presented in both countries, Ruggedness is in a relatively higher-presence in the US websites and Sophistication in China (shown in Table 3 and Fig. 2). Garolera corresponded Sophistication with hierarchy, characterized with high power distance cultures (like China).

TABLE 7:

KEY WORDS AND FREQUENCIES ASSOCIATED WITH RUGGEDNESS IN “ABOUT US” OF CHINESE AND US ENERGY COMPANIES’ WEBSITES

\begin{tabular}{llll}
\hline Dimension & Frequency Rank & CHINA & US \\
\hline \multirow{4}{*}{ Ruggedness } & 1 & Hard (7) & Testing (6) \\
& 2 & Physical (6) & Hard (5) \\
& 3 & Western (5) & Endeavor (2) \\
& 4 & Tough (3) & Robust (2) \\
\hline
\end{tabular}

TABLE 8:

KEy WORdS AND FREQUENCIES ASSOCIATED WITH SOPHISTICATION IN “ABOUT US” OF CHINESE AND US ENERGy COMPANIES' WEBSITES

\begin{tabular}{llll}
\hline Dimension & Frequency Rank & CHINA & US \\
\hline & 1 & Refined (17) & Refined (22) \\
Sophistication & 2 & Excellent (11) & Attractive (1) \\
& 3 & Precious (4) & Prestigious (1) \\
& 4 & Beautiful (1) & Striking (1) \\
\hline
\end{tabular}

There are not many differences between key word lists in Table 7 and 8 . There are two words worth attention, listed as follows.

CHINA

- An excellent corporate culture will help lay down an ever-lasting foundation for an enterprise. CNMC holds and 
implements the idea that "cultural power will guide productivity"

-... is looking to develop various businesses in cooperation with external partners

-...began selling jet fuel to western Africa. Our gasoline market share in Pakistan and the United Arab Emirates kept increasing....

Excellent, Western and External appear frequently in Chinese websites in comparison to western companies, reflecting China's (MAS scored 66, US 62) aggressiveness to compete with foreign partners by stressing their companies' performance and achievements, which is among online cultural markers of Masculine (MAS), as summarized by Singh \& Matsuo. Clear gender roles, explicit comparison and use of superlatives are cultural markers of Masculinity. Masculinity cultures are characterized by competition and social achievement.

As to RQ 1, cultural variation in values and needs does influence energy companies' projection of brand personality online in ways of dominating dimensions and word choices in expressing the same trait, although the commercial and technological globalization has been narrowing cultural gaps. The personality of home country's culture does have an influence on brand personality. Indeed, China and US energy companies' websites have some differences because of different cultures. Even expressing the same personality dimension, Chinese companies are partially using words which are not culturally adapted. For instance, as for Competence and Sincerity, Chinese companies may choose more words like Responsible and Honest related to corporate social responsibility. CSR demonstrates effects on customer satisfaction and loyalty, and company suitability, so shall be included as an aspect of corporate brand reputation. As to RQ 2, all those show energy stress more safe, reliable and stable. More individualism-oriented words like Independent, Single and Challenge are favored by western customers to perceive personalities like Sincerity and Excitement. By enforcing these personality traits, it is conductive for companies to project a positive image in the global market.

\section{CONCLUSIONS AND LimitATIONS}

With the Internet, companies have an unparalleled access to international customers. Being aware of the significance of online corporate communication, Chinese companies are already investing considerable resources in building their English website. If these websites are simply translated from Chinese and fail to communicate appropriate identify and personality of brands, these expenditure may be wasted, or even counterproductive. This study finds that although they have designed English websites with "about us" section and shared similar distributions, Chinese energy companies are still significantly different from the US in terms of language choice and occurrence on all the five corporate brand personality dimensions. The linguistic differences in Chinese and US corporate brand personality indicators are relevant to their cultural differences. Even when expressing the same personality traits, Chinese companies tend to use words that are not adapted to western culture.

Generally, customers prefer to browse websites in their own country domain. Practitioners always want to figure out what influences customers' preferences and perception of brands. Barney asserts that culture can be a source of competitive advantage when it involves a unique personality. Therefore, it is beneficial for foreign-market-oriented Chinese companies to localize their websites according to local tastes and preferences, which helps to make their brand personality in consistency with customers' own personality increasing their preferences for the product and corporate without being too deeply concerned with China's Collectivist, high-PD, and Masculine culture.

Although both semantic and technical difficulties may arise in translating brand expressions, the very first step of website localization for Chinese companies is building English corporate websites with more information about Customer Affair and gallery disclosed in "about us". Second, in-depth understanding of words and expression modes associated with brand personality dimensions not only helps practitioners improve their knowledge of global identity positioning of Chinese energy companies in comparison with US, but also provides insights into how to align website languages with international perceptions of brands by strengthening or downplaying particular brand personality dimensions.

Nowadays China introduces the "going out" strategy to encourage its companies to invest overseas, with a main objective to promote brand recognition of Chinese companies in the US market. Unfortunately, Chinese companies were ill prepared to manage cultural differences and be negatively received in in overseas market, especially the US. Therefore, in addition to upgrade products and services, Chinese companies need to better tailor marketing materials in need of target customers, evaluate underperforming brands with respect to brand-customer personality incongruity, build and manage their unique corporate identity, and eventually improve their corporate image and corporate reputation, which are crucial elements of competitiveness against the well-established foreign companies (Ingenhoff \& Fuhrer, 2010).

In conclusion, the computerized content analysis illustrated here can be of strategic assistance to managers in portraying and managing brand images and personalities by focusing on the words used in sites. When developing particular brand personality, managers shall be aware that customers' perception may be not in line with their orientation due to cultural differences. Consumers tend to choose brands with personalities that are congruent with their self-concepts. A strong and favorable brand personality can help build more positive brand associations, and reinforce corporate identity, 错误! 未定义书签。] which can sustain companies' unique competitive advantages, improve customers' satisfaction and loyalty, influence their buying decision, and then increase companies' turnover, profits, market capitalization and stakeholders' value. 
Some limitations shall be taken into consideration when interpreting and furthering the findings, although this study has advanced online communication literature by extending previous research with empirical evidences from the perspective of cross-cultural corpus analysis, and provides practical implications in relation to how Chinese companies express intended brand personality dimensions in websites designed for foreign users. First, the statistics are only based on the five dimensions instead of the fifteen attributes specifically. Second, it can be more insightful to compare online and offline expressions of brand personality dimensions. Third, a China-specific brand personality scale can be constructed considering Aaker's scale is developed on the US base. Finally, similar studies can be extended to other countries or industries, and correlate with more performance measures like brand ranking, market capitalization, profit, and P/E.

\section{REFERENCES}

[1] Aaker J L. (1997). Dimensions of Brand Personality. Journal of Marketing Research, 34(3):347-356.

[2] Aaker J L, Benet-Martínez V, Garolera J. (2001). Consumption symbols as carriers of culture: a study of Japanese and Spanish brand personality constructs. Journal of Personality \& Social Psychology, 81(3):492.

[3] Abdullah, Z., Nordin, S. M., \& Aziz, Y. A. (2013). Building a unique online corporate identity. Marketing Intelligence \& Planning, 31(5):451-471.

[4] Arnould, E. J., \& Thompson, C. J. (2005). Consumer culture theory (CCT): Twenty years of research. Journal of consumer research, 31(4): 868-882.

[5] Arora, R., \& Stoner, C. (2009). A mixed method approach to understanding brand personality. Journal of Product \& Brand Management, 18(4):272-283.

[6] Booth, N., \& Matic, J. A. (2011). Mapping and leveraging influencers in social media to shape corporate brand perceptions. Corporate Communications: An International Journal, 16(3):184-191.

[7] Breeze, R. (2013). Corporate Discourse. Corporate discourse. Bloomsbury.

[8] Burgmann I, Kitchen P J, Williams R. (2006). Does culture matter on the web? Marketing Intelligence \& Planning, 24(1):62-76.

[9] Burnett, G. and Buerkle, H. (2004). Information exchange in virtual communities: a comparative study, Journal of Computer-Mediated Communication, 9(2):10-12.

[10] Chao, M. C. H., Singh, N. \& Chen, Y. N. (2012). Web site localization in the Chinese market. Journal of electronic commerce research, 13(1):33.

[11] Davies, G., et al. (2001). The personification metaphor as a measurement approach for corporate reputation. Corporate Reputation Review, 4(2): 113-127.

[12] Dowling, G. R. (2001). Breaking compromises. Journal of Brand Management, 8(4):369-370(2).

[13] Hofstede, G. H. (1984). Culture's consequences: international differences in work-related values. London: Sage Publications.

[14] Hofstede G. (2010). Cultures and Organizations: Software of the Mind. ( $3^{\text {rd }}$ rev. ed.). New York: McGraw-Hill USA.

[15] Ingenhoff, D. \& Fuhrer, T. (2010). Positioning and differentiation by using brand personality attributes: do mission and vision statements contribute to building a unique corporate identity?. Corporate Communications an International Journal, 15(1):83-101.

[16] Judith Evans, et al. (2001). Designing Corporate Identity: graphic design as a business strategy. US: Rockport Publishers.

[17] Keller, K. \& Richey, K. (2006). The importance of corporate brand personality traits to a successful 21st century business. Journal of Brand Management, 14(1):74-81.

[18] Maehle, N., Otnes, C. \& Supphellen, M. (2011). Consumers' perceptions of the dimensions of brand personality. Journal of Consumer Behaviour, 10(5):290-303.

[19] Okazaki, S. (2006). Excitement or sophistication? a preliminary exploration of online brand personality. International Marketing Review, 23(3):279-303.

[20] Opoku, R. \& Hinson, R. (2006). Online brand personalities: an exploratory analysis of selected african countries. Place Branding, 2(2):118-129.

[21] Rogers, J. L., Van Buskirk, A., \& Zechman, S. L. (2011). Disclosure tone and shareholder litigation. The Accounting Review, 86(6):2155-2183.

[22] Simoes, C., Singh, J. \& Perin, M. G. (2015). Corporate brand expressions in business-to-business companies' websites: evidence from Brazil and India. Industrial Marketing Management, (51):59-68.

[23] Singh N, Pereira A. (2005). The culturally customized web site: customizing web sites for the global marketplace. Multilingual, 11(63):125-126.

[24] Sung, Y. \& Tinkham, S. F. (2005). Brand personality structures in the united states and Korea: common and culture-specific factors. Journal of Consumer Psychology, 15(4):334-350.

[25] Vence, D. L. (2005). Net serves as best tool to connect with Hispanics. Marketing News. 39(14), p29.

Xiaohui Shan, born in China on Dec. 24, 1978, received a Master's degree in Applied Linguistics awarded by University of International Business and Economics, Beijing China, in 2004.

She has been teaching business English courses in the Department of Foreign Languages at China Women's University since graduation in 2004 and offered the title of Lecturer in 2007. Her current job location is 1 Yuhuidonglu Chaoyang District Beijing China 100101. Her major research interests focus on Intercultural Business Communication. Publications: An Analysis of IELTS Writing from Cohesion Theory Perspective, Foreign Languages and Foreign Language Research, 2010; Differences in Time Orientation between the Chinese and Germans, Language and Culture, 2013. 
Qian Wang was born in Shandong China in 1993. She received her Bachelor degree in Literature from China Women's University, China in 2017. She is specialized in Cross-cultural business communication. 